\title{
Hemodynamic characteristics associated with cerebral aneurysm formation in patients with carotid occlusion
}

\author{
Sophia F. Shakur, MD, Ali Alaraj, MD, Nasya Mendoza-Elias, BS, Muhammad Osama, MD, and \\ Fady T. Charbel, MD
}

Department of Neurosurgery, University of Illinois at Chicago, Illinois

\begin{abstract}
OBJECTIVE The pathogenesis of cerebral aneurysms in patients with internal carotid artery (ICA) occlusion is hypothesized to be hemodynamic. For the first time, the authors quantify the hemodynamic characteristics associated with aneurysm formation in patients with ICA occlusion.
\end{abstract}

METHODS Records of patients with unilateral ICA stenosis or occlusion $\geq 90 \%$ who underwent hemodynamic assessment before treatment using quantitative MR angiography were retrospectively reviewed. The patients were classified into 2 groups based on the presence or absence of aneurysms. The hemodynamic parameters of flow volume rate, flow velocity, and wall shear stress (WSS) were measured in each vessel supplying collateral flow-bilateral $A_{1}$ segments and bilateral posterior communicating arteries-and then compared between the groups.

RESULTS A total of 36 patients were included (8 with and 28 without aneurysms). The mean flow $(72.3 \mathrm{vs} 48.9 \mathrm{ml} / \mathrm{min}$, $p=0.10)$, flow velocity (21.1 vs $12.7 \mathrm{~cm} / \mathrm{sec}, p=0.006)$, and WSS (22.0 vs 12.3 dynes $/ \mathrm{cm}^{2}, p=0.003$ ) were higher in the $A_{1}$ segment contralateral to the side of the patent ICA in patients with versus without aneurysms. All de novo or growing aneurysms in our cohort were located on the anterior communicating artery ( $A C O A)$ or $P_{1}$ segment.

CONCLUSIONS Flow velocity and WSS are significantly higher across the ACoA in patients who harbor an aneurysm, and de novo or growing aneurysms are often located on collateral vessels. Thus, robust primary collaterals after ICA occlusion may be a contributing factor in cerebral aneurysm formation.

https://thejns.org/doi/abs/10.3171/2017.11.JNS171794

KEYWORDS aneurysm; carotid occlusion; cerebral; de novo; flow; hemodynamics; shear stress; vascular disorders

$\mathrm{C}$ EREBRAL aneurysms are generally thought to be acquired lesions that develop during adulthood. ${ }^{6,10}$ Accordingly, the main risk factors linked to cerebral aneurysm formation and growth are older age, hypertension, and cigarette smoking. ${ }^{6,8,12} \mathrm{He}-$ modynamic stresses are also thought to play a role in the pathogenesis of aneurysms, but this hypothesis is largely based on anecdotal evidence of the high occurrence of de novo aneurysms in patients with internal carotid artery (ICA) occlusion..$^{1,4,5,7,13}$ In this study, we aimed to determine the hemodynamic characteristics associated with cerebral aneurysm formation in patients with ICA occlusion with the aid of quantitative MR angiography (QMRA).

\section{Methods \\ Patient Selection}

After receiving institutional review board approval, we retrospectively reviewed the records of patients with unilateral ICA stenosis or occlusion $\geq 90 \%$ who were evaluated at our institution between 2006 and 2016. Patients were included if they underwent hemodynamic assessment using QMRA before treatment. Patients were classified into 2 groups based on the presence or absence of aneurysms as documented on digital subtraction angiography. The degree of ICA stenosis was determined based on digital subtraction angiography findings using the North American Symptomatic Carotid Endarterectomy Trial criteria. ${ }^{2}$

\section{Flow Volume Rate, Flow Velocity, and Wall Shear Stress Measurements}

In all patients, the quantitative vessel flow volume rate, flow velocity, and diameter of the extracranial and intracranial arteries were measured using QMRA at the time the ICA occlusion was diagnosed. This technique has been

ABBREVIATIONS $\mathrm{ACOA}=$ anterior communicating artery; ICA = internal carotid artery; $\mathrm{PCOA}=$ posterior communicating artery; $\mathrm{QMRA}=$ quantitative MR angiography; WSS = wall shear stress.

SUBMITTED July 22, 2017. ACCEPTED November 10, 2017.

INCLUDE WHEN CITING Published online May 4, 2018; DOI: 10.3171/2017.11.JNS171794. 
TABLE 1. Clinical, aneurysm, and hemodynamic characteristics of patients with and without aneurysms

\begin{tabular}{|c|c|c|}
\hline Variable & Aneurysm Absent $(n=28)$ & Aneurysm Present $(n=8)$ \\
\hline Mean age, yrs (range) & $58(35-74)$ & $59(36-71)$ \\
\hline \multicolumn{3}{|l|}{$\%$ of patients } \\
\hline Male sex & 61 & 38 \\
\hline ICA occlusion & 61 & 63 \\
\hline Hypertension & 61 & 88 \\
\hline Smoking & 61 & 75 \\
\hline \multicolumn{3}{|l|}{ Aneurysm location, no. } \\
\hline Paraclinoid ICA & & 2 \\
\hline $\mathrm{ACoA}$ & & 3 \\
\hline Basilar tip & & 1 \\
\hline$P_{1}$ & & 1 \\
\hline PICA & & 1 \\
\hline Mean aneurysm diameter, mm (range) & & $6.6(2.5-12.2)$ \\
\hline \multicolumn{3}{|l|}{ Hemodynamics } \\
\hline Mean contralat $\mathrm{A}_{1}$ flow, $\mathrm{ml} / \mathrm{min}$ (range) & $48.9 \pm 35.0(7.2-135.0)$ & $72.3 \pm 28.6(30.0-116.7)$ \\
\hline Mean contralat $\mathrm{A}_{1}$ flow velocity, $\mathrm{cm} / \mathrm{sec}$ (range) & $12.7 \pm 7.0(3.7-35.2)$ & $21.1 \pm 4.5(12.0-26.3)$ \\
\hline Mean contralat $\mathrm{A}_{1}$ WSS, dynes/cm² (range) & $12.3 \pm 7.1(4.6-18.8)$ & $22.0 \pm 5.9(10.5-30.0)$ \\
\hline
\end{tabular}

PICA = posterior inferior cerebellar artery.

described and validated previously $y^{3,15}$ and was implemented using the commercially available software Noninvasive Optimal Vessel Analysis (NOVA, VasSol, Inc.). Hemodynamic parameters were measured in all major extracranial and intracranial vessels, including each vessel supplying collateral flow: the bilateral $\mathrm{A}_{1}$ segments and bilateral posterior communicating arteries (PCoAs).

Once blood flow and vessel diameter were measured, wall shear stress (WSS) was calculated using the HagenPoiseuille equation: WSS $=32 \mu \mathrm{Q} / \pi \mathrm{D}^{3}$, where WSS is in dynes $/ \mathrm{cm}^{2}$, Q is the volumetric flow rate in $\mathrm{ml} / \mathrm{sec}$, and D is the vessel diameter in $\mathrm{cm} ; \mu$ is the blood viscosity in poise and was assumed to be constant ( 0.035 poise). This method was previously described by Zhao et al. ${ }^{16}$

\section{Statistical Analysis}

Hemodynamic parameters were compared between patients with and without aneurysms using the independent 2-tailed Student t-test. Analyses were performed using IBM SPSS (version 24, IBM Corp.); $\mathrm{p} \leq 0.05$ was considered statistically significant.

\section{Results}

\section{Patient Characteristics}

A total of 36 patients were included in this study. Among these patients, there were 28 without and 8 with a cerebral aneurysm. Cohort characteristics are summarized in Table 1.

\section{Aneurysm Characteristics}

Aneurysm characteristics are summarized in Table 1, and hemodynamic parameters of patients with aneurysms are provided in Table 2 . Among the 8 patients with an- eurysms, 5 patients were incidentally found to harbor a cerebral aneurysm at the time they were diagnosed with ICA occlusion, and 3 patients (8.3\% of study cohort) had de novo or growing aneurysms detected during follow-up.

Of the incidental aneurysms, 2 originated from the paraclinoid ICA, 1 from the anterior communicating artery (ACoA), 1 from the basilar tip, and 1 from the posterior inferior cerebellar artery. Among all patients with aneurysms, ICA flow but not WSS in the patent ICA was the highest in the setting of the 2 paraclinoid ICA aneurysms (441 $\mathrm{ml} / \mathrm{min}$ and $394 \mathrm{ml} / \mathrm{min}$, mean flow $337 \mathrm{ml} / \mathrm{min}$, range $259-441 \mathrm{ml} / \mathrm{min}$ ). Basilar artery flow and WSS were not higher in the setting of the basilar tip aneurysm.

Of the de novo or growing aneurysms, 2 originated from the ACoA and 1 from the $\mathrm{P}_{1}$ segment ipsilateral to the occluded ICA. One patient presented with rupture of a de novo ACoA aneurysm 7 years after ICA coil sacrifice for treatment of a giant cavernous ICA aneurysm, and another patient presented with rupture of a de novo $\mathrm{P}_{1}$ segment aneurysm 4 years after ICA coil sacrifice. The third patient had atherosclerotic ICA occlusion and an incidental ACoA aneurysm that enlarged from $2 \mathrm{~mm}$ to $4 \mathrm{~mm}$ over 4 years. Hemodynamic measurements before and after aneurysm development were only available in the patient with the growing aneurysm; the WSS in the contralateral $\mathrm{A}_{1}$ segment increased from 19.3 dynes $/ \mathrm{cm}^{2}$ to 21.7 dynes $/ \mathrm{cm}^{2}$ as the aneurysm doubled in size.

\section{Hemodynamic Characteristics in Patients With Versus Without Aneurysms}

Hemodynamic values in the $\mathrm{A}_{1}$ segment ipsilateral to the side of the patent ICA did not significantly vary between patients with versus without aneurysms (mean flow $165.2 \pm 72.5$ vs $164.3 \pm 92.7 \mathrm{ml} / \mathrm{min}, \mathrm{p}=0.98$; flow veloc- 
TABLE 2. Hemodynamic characteristics of patients with aneurysms

\begin{tabular}{|c|c|c|c|c|c|c|c|c|c|c|c|c|c|c|}
\hline \multirow[b]{2}{*}{$\begin{array}{l}\text { Case } \\
\text { No. }\end{array}$} & \multirow[b]{2}{*}{$\begin{array}{l}\text { Aneurysm } \\
\text { Location }\end{array}$} & \multirow{2}{*}{$\begin{array}{c}\text { Aneurysm } \\
\text { Diameter } \\
(\mathrm{mm})\end{array}$} & \multicolumn{4}{|c|}{ Flow (ml/min) } & \multicolumn{4}{|c|}{ Flow Velocity $(\mathrm{cm} / \mathrm{sec})$} & \multicolumn{4}{|c|}{ WSS (dynes/cm²) } \\
\hline & & & $\begin{array}{c}\text { Ipsilat } \\
A_{1}\end{array}$ & $\begin{array}{c}\text { Contralat } \\
A_{1}\end{array}$ & $\begin{array}{l}\text { Ipsilat } \\
\text { PCoA }\end{array}$ & $\begin{array}{c}\text { Contralat } \\
\text { PCoA }\end{array}$ & $\begin{array}{c}\text { Ipsilat } \\
\mathrm{A}_{1}\end{array}$ & $\begin{array}{c}\text { Contralat } \\
A_{1}\end{array}$ & $\begin{array}{l}\text { Ipsilat } \\
\text { PCoA }\end{array}$ & $\begin{array}{c}\text { Contralat } \\
\text { PCoA }\end{array}$ & $\begin{array}{c}\text { Ipsilat } \\
A_{1}\end{array}$ & $\begin{array}{c}\text { Contralat } \\
A_{1}\end{array}$ & $\begin{array}{l}\text { Ipsilat } \\
\text { PCoA }\end{array}$ & $\begin{array}{c}\text { Contralat } \\
\text { PCoA }\end{array}$ \\
\hline 1 & $\begin{array}{l}\text { Paraclinoid } \\
\text { ICA }\end{array}$ & 8.6 & 259.6 & 116.7 & - & 45.3 & 42.1 & 26.3 & - & 19.5 & 33.1 & 23.3 & - & 25.3 \\
\hline 2 & $\begin{array}{l}\text { Paraclinoid } \\
\text { ICA }\end{array}$ & 3.5 & 40.2 & 40.3 & - & - & 22.4 & 20.4 & - & - & 29.9 & 30.0 & - & - \\
\hline 3 & $\begin{array}{c}\mathrm{ACoA} \text { (de } \\
\text { novo) }\end{array}$ & 5 & - & 74.1 & - & - & - & 22.9 & - & - & - & 25.1 & - & - \\
\hline 4 & $\begin{array}{l}\text { ACoA } \\
\text { (growing) }\end{array}$ & 4 & 142.5 & 89.1 & - & 30.3 & 34.6 & 22.6 & - & 9.1 & 31.4 & 21.7 & - & 9.2 \\
\hline 5 & $\mathrm{ACoA}$ & 2.5 & 175.4 & 93.0 & 9.0 & - & 41.1 & 23.1 & 2.7 & - & 38.7 & 22.7 & 3.0 & - \\
\hline 6 & Basilar tip & 12.2 & 176.4 & 58.0 & - & 47.9 & 23.6 & 12.0 & - & 10.1 & 16.4 & 10.5 & - & 8.7 \\
\hline 7 & $P_{1}$ (de novo) & 12 & - & 30.0 & - & 82.4 & - & - & - & - & - & - & - & - \\
\hline 8 & PICA & 5 & 196.9 & 77.0 & - & 15.1 & 29.7 & 20.3 & - & 8.2 & 23.1 & 20.9 & - & 11.2 \\
\hline
\end{tabular}

$-=$ hemodynamic parameter not measured.

ity $32.3 \pm 8.5$ vs $34.9 \pm 10.9 \mathrm{~cm} / \mathrm{sec}, \mathrm{p}=0.59$; and WSS $28.8 \pm 7.9$ vs $32.6 \pm 9.3$ dynes $/ \mathrm{cm}^{2}, \mathrm{p}=0.36$ ). However, $\mathrm{A}_{1}$ segment hemodynamics contralateral to the side of the patent ICA were higher in patients with aneurysms (mean flow $72.3 \pm 28.6$ vs $48.9 \pm 35.0 \mathrm{ml} / \mathrm{min}, \mathrm{p}=0.10$; flow velocity $21.1 \pm 4.5$ vs $12.7 \pm 7.0 \mathrm{~cm} / \mathrm{sec}, \mathrm{p}=0.006$; and WSS $22.0 \pm 5.9$ vs $12.3 \pm 7.1$ dynes $/ \mathrm{cm}^{2}, \mathrm{p}=0.003$ ) (Table 1 and Fig. 1).

Among patients without aneurysms, PCoA hemody- namics ipsilateral to the side of the patent ICA were as follows: mean flow $26.1 \pm 21.8 \mathrm{ml} / \mathrm{min}$, mean flow velocity $9.9 \pm 7.7 \mathrm{~cm} / \mathrm{sec}$, and WSS $9.5 \pm 6.4$ dynes $/ \mathrm{cm}^{2}$. PCoA hemodynamics contralateral to the side of the patent ICA were as follows: mean flow $45.1 \pm 30.1 \mathrm{ml} / \mathrm{min}$, mean flow velocity $17.9 \pm 10.3 \mathrm{~cm} / \mathrm{sec}$, and WSS $22.3 \pm 12.9$ dynes/ $\mathrm{cm}^{2}$. PCoA hemodynamics in patients with aneurysms are provided in Table 2 but were not statistically compared with patients without aneurysms, given the smaller sam-

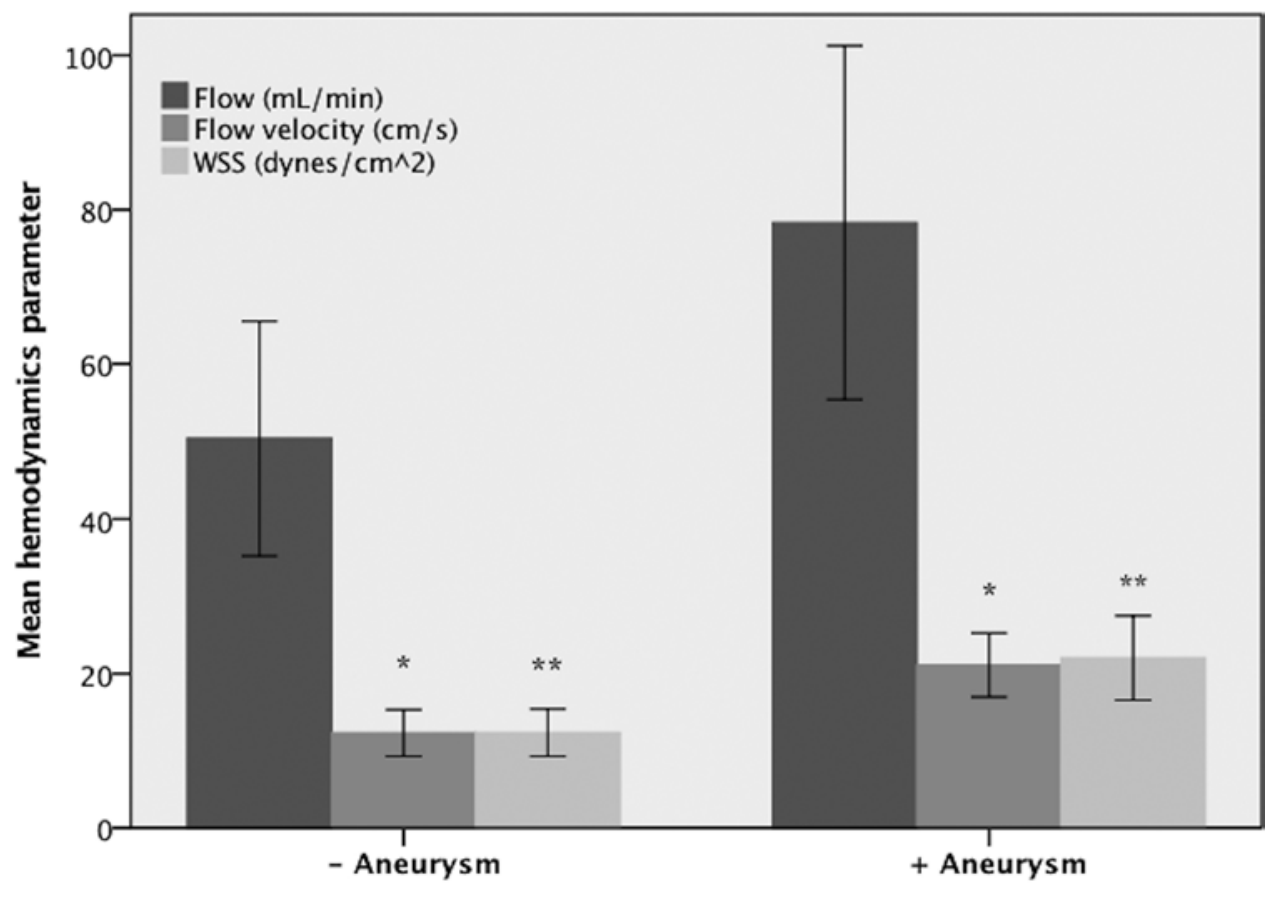

Error bars: $95 \% \mathrm{Cl}$

FIG. 1. Bar graph showing hemodynamic characteristics in patients with versus without aneurysms. The mean flow, flow velocity, and WSS in the $A_{1}$ segment contralateral to the patent ICA are higher in patients with aneurysms. ${ }^{*}$ and ${ }^{* *} p \leq 0.05$. 


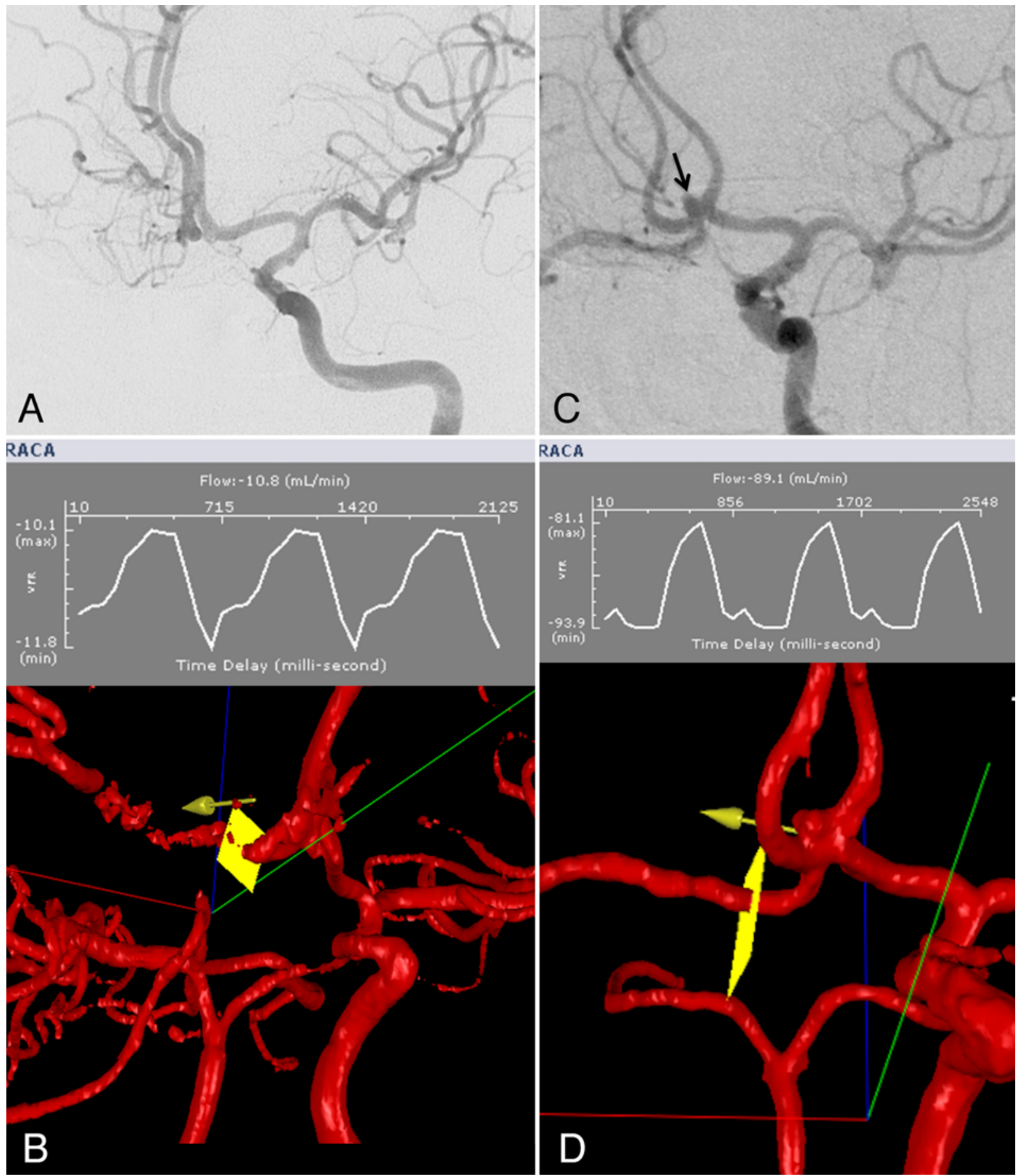

FIG. 2. Illustrative cases. $A$ and $B$ : Digital subtraction angiogram $(A)$ and $Q M R A$ image $(B)$ obtained in a patient without an aneurysm. The flow in the contralateral $A_{1}$ segment is $10.8 \mathrm{ml} / \mathrm{min}$ and the WSS is 6.0 dynes $/ \mathrm{cm}^{2}$. C and D: Images obtained in a patient with an $\mathrm{ACOA}$ aneurysm. Digital subtraction angiogram $(\mathrm{C})$. The arrow identifies the aneurysm on the digital subtraction angiogram, left ICA injection, oblique projection. QMRA image (D). The yellow arrow and plane indicate the location of the contralateral $A_{1}$ segment flow $(89.1 \mathrm{ml} / \mathrm{min})$ and WSS $\left(21.7\right.$ dynes $\left./ \mathrm{cm}^{2}\right)$ measurements. Figure is available in color online only. 
ple size compared with the $A_{1}$ segment data set. However, PCoA flow ipsilateral to the de novo $\mathrm{P}_{1}$ segment aneurysm in our cohort $(82.4 \mathrm{ml} / \mathrm{min})$ was the highest among patients with aneurysms and was much higher than mean PCoA flow in patients without aneurysms.

\section{Discussion}

An understanding of the formation and growth of cerebral aneurysms is imperative, given the high morbidity and mortality rates associated with ruptured aneurysms. While hemodynamic stresses have been implicated in the pathogenesis of aneurysms, not all de novo aneurysms are associated with ICA occlusion, and not all patients with ICA occlusion develop aneurysms. ${ }^{1,4-8,11-13}$ Thus, our current understanding of the pathogenesis of cerebral aneurysms remains incomplete.

The hemodynamic perspective has been investigated using computational fluid dynamics and has yielded conflicting conclusions regarding WSS. ${ }^{7,9}$ In this study for the first time we used QMRA to quantify and compare hemodynamic parameters in ICA occlusion patients with and without aneurysms. We found that flow velocity and WSS are significantly higher across the ACoA in patients who harbor an aneurysm. Additionally, all de novo or growing aneurysms in our cohort were located on vessels providing collateral blood supply, namely the ACoA and $\mathrm{P}_{1}$ segment. Illustrative cases depicting one patient without an aneurysm and another patient with an aneurysm are shown in Fig. 2.

Our results suggest that increased WSS can lead to cerebral aneurysm formation, corroborating previous studies that cite WSS as an important biomechanical stimulus for molecular changes associated with aneurysm development. ${ }^{14}$ Our findings also support a multifactorial model for aneurysm formation since patients with aneurysms in our cohort had a higher prevalence of hypertension and smoking in addition to elevated flow velocity and WSS (Table 1). We also demonstrated that patients with ICA occlusion are a subgroup at higher risk for de novo or growing aneurysms (3/36 patients [8.3\%], present study vs $26 / 2153$ patients [1.2\%], Wang et al. ${ }^{12}$ ). Consequently, screening for de novo aneurysms may be appropriate in this patient subset. Further studies may identify a WSS threshold indicative of a hyperdynamic state susceptible to aneurysm formation among patients with ICA occlusion.

Limitations of this study are its retrospective design and small sample size. Only 3 de novo or growing aneurysms were identified, and hemodynamic measurements before and after aneurysm development were only available in the patient with the growing aneurysm; the WSS of the contralateral $\mathrm{A}_{1}$ segment increased from 19.3 dynes $/ \mathrm{cm}^{2}$ to 21.7 dynes $/ \mathrm{cm}^{2}$ as the aneurysm doubled in size. Another limitation is that PCoA hemodynamics were not statistically compared between patients with and without aneurysms given that the sample size was smaller than that of the $\mathrm{A}_{1}$ segment data set. PCoA hemodynamics measured using QMRA are less consistently obtained than those measured in other vessels, particularly when the PCoA is small or absent. Our small sample size yields preliminary results that require confirmatory investigation. Potential variability in the data reflects the fact that blood flow, flow velocity, and WSS are physiological parameters. Ipsilateral and contralateral hemodynamics were examined to account for potential confounders, such as age, heart rate, and blood pressure. Finally, while the Hagen-Poiseuille equation assumes steady, laminar flow of a newtonian fluid in straight rigid vessels, it provides a useful estimate of WSS.

\section{Conclusions}

Flow velocity and WSS are significantly higher across the ACoA in patients who harbor an aneurysm, and de novo or growing aneurysms are often located on collateral vessels. These preliminary results suggest that robust primary collaterals after ICA occlusion may be a contributing factor in cerebral aneurysm formation.

\section{References}

1. Arnaout OM, Rahme RJ, Aoun SG, Daou MR, Batjer HH, Bendok BR: De novo large fusiform posterior circulation intracranial aneurysm presenting with subarachnoid hemorrhage 7 years after therapeutic internal carotid artery occlusion: case report and review of the literature. Neurosurgery 71:E764-E771, 2012

2. Barnett HJM, Taylor DW, Haynes RB, Sackett DL, Peerless SJ, Ferguson GG, et al: Beneficial effect of carotid endarterectomy in symptomatic patients with high-grade carotid stenosis. N Engl J Med 325:445-453, 1991

3. Calderon-Arnulphi M, Amin-Hanjani S, Alaraj A, Zhao M, Du X, Ruland S, et al: In vivo evaluation of quantitative MR angiography in a canine carotid artery stenosis model. AJNR Am J Neuroradiol 32:1552-1559, 2011

4. Dyste GN, Beck DW: De novo aneurysm formation following carotid ligation: case report and review of the literature. Neurosurgery 24:88-92, 1989

5. Fujiwara S, Fujii K, Fukui M: De novo aneurysm formation and aneurysm growth following therapeutic carotid occlusion for intracranial internal carotid artery (ICA) aneurysms. Acta Neurochir (Wien) 120:20-25, 1993

6. Juvela S, Poussa K, Porras M: Factors affecting formation and growth of intracranial aneurysms: a long-term follow-up study. Stroke 32:485-491, 2001

7. Kono K, Masuo O, Nakao N, Meng H: De novo cerebral aneurysm formation associated with proximal stenosis. Neurosurgery 73:E1080-E1090, 2013

8. Koroknay-Pál P, Niemelä M, Lehto H, Kivisaari R, Numminen J, Laakso A, et al: De novo and recurrent aneurysms in pediatric patients with cerebral aneurysms. Stroke 44:1436-1439, 2013

9. Meng H, Tutino VM, Xiang J, Siddiqui A: High WSS or low WSS? Complex interactions of hemodynamics with intracranial aneurysm initiation, growth, and rupture: toward a unifying hypothesis. AJNR Am J Neuroradiol 35:1254-1262, 2014

10. Ostergaard JR: Risk factors in intracranial saccular aneurysms. Aspects on the formation and rupture of aneurysms, and development of cerebral vasospasm. Acta Neurol Scand 80:81-98, 1989

11. Shakur SF, Amin-Hanjani S, Mostafa H, Charbel FT, Alaraj A: Hemodynamic characteristics of cerebral arteriovenous malformation feeder vessels with and without aneurysms. Stroke 46:1997-1999, 2015

12. Wang JY, Smith R, Ye X, Yang W, Caplan JM, Radvany MG, et al: Serial imaging surveillance for patients with a history 
of intracranial aneurysms: risk of de novo aneurysm formation. Neurosurgery 77:32-43, 2015

13. Wang YY, Rosenfeld JV, Lyon SM, O'Brien BJ: Rapid development of a de novo intracranial aneurysm following carotid occlusion. J Clin Neurosci 15:324-330, 2008

14. Wang Z, Kolega J, Hoi Y, Gao L, Swartz DD, Levy EI, et al: Molecular alterations associated with aneurysmal remodeling are localized in the high hemodynamic stress region of a created carotid bifurcation. Neurosurgery 65:169-178, 2009

15. Zhao M, Charbel FT, Alperin N, Loth F, Clark ME: Improved phase-contrast flow quantification by three-dimensional vessel localization. Magn Reson Imaging 18:697706,2000

16. Zhao X, Zhao M, Amin-Hanjani S, Du X, Ruland S, Charbel FT: Wall shear stress in major cerebral arteries as a function of age and gender-a study of 301 healthy volunteers. J Neuroimaging 25:403-407, 2015

\section{Disclosures}

Dr. Alaraj: consultant for Cordis-Codman. Dr. Charbel: consultant for Transonic Inc.

\section{Author Contributions}

Conception and design: Charbel, Alaraj. Acquisition of data: Shakur, Mendoza-Elias, Osama. Analysis and interpretation of data: Shakur. Drafting the article: Shakur. Critically revising the article: Charbel, Shakur, Alaraj. Reviewed submitted version of manuscript: all authors. Statistical analysis: Shakur. Administrative/technical/material support: Charbel. Study supervision: Charbel.

\section{Correspondence}

Fady T. Charbel: University of Illinois at Chicago, IL. fcharbel@ uic.edu. 